\title{
Standby or Breakup? How Brands in China Respond When Celebrity Endorsers Get Involved in Scandals
}

\author{
Jiaqi Liu \\ School of Journalism and Communication, The Chinese University of Hong Kong, Hong Kong SAR \\ liujiaqitina@126.com
}

Keywords: Celebrity endorsement, Crisis communication, Social legitimacy, Legal legitimacy, Internal attribution, External Attribution, Response strategy.

\begin{abstract}
Celebrity endorsement, a common strategy used in marketing and advertising is a double-edged sword for brands. The established association with celebrity endorsers can bring not only desirable potentials to brands but also crisis when endorsers get involved in scandals. Current literature on this type of crisis lacks focuses on Chinese culture context, analysis of response strategy, and empirical research design. To fill these gaps, this paper adopts case study and content analysis to investigate four influential scandals happened last year in China and the crisis management strategies of affected brands. Comments and reposts of nine Sina Weibo posts were collected for analysis. Five of them are the official responding posts of involved celebrities, while the other four are posts of affected brands. Findings support that in China social legitimacy violation and internal attribution of crisis responsibility will cause a more negative influence on the celebrity endorser's reputation than legal legitimacy violation and external attribution of crisis responsibility, respectively. Brands shall determine whether to terminate the endorsement contract or not according to public attitude towards the scandal. Contrary to other suggestions, this research demonstrates that brands can use "silence strategy" to manage celebrity endorsement crisis.
\end{abstract}

\section{Introduction}

Celebrity endorsement is a widely-adopted strategy in the marketing and advertising industry. Research shows that about 25 percent of advertisements and 20 percent of commercials feature a famous person (Gass \& Seiter, 2015). In China, this practice is even more popular. According to research conducted by DoMarketing (2012), more than 30 percent of all Chinese TV commercials use celebrity endorsement, and the endorsement fee is usually a substantial amount.

The generous investment of various brands on this tactic is understandable, because celebrities' positive qualities, such as popularity, attractiveness, desirable personality traits and trustworthiness, can be associated with the brands, thus help improve the brands' image and encourage trial as well as purchase (Chan, Leung Ng, \& Luk, 2013; Erdogan,1999). Another research also proved that the sales can be boosted by celebrity spokesperson by about 20 percent (Gass \& Seiter, 2015). This effectiveness can be explained by the Meaning Transfer Model (McCracken, 1989), which suggests that celebrities exert influence by transferring cultural meaning to products and then from products to consumers (Miller \& Allen, 2012).

Association, however, is not always favorable. When the celebrity endorser gets involved in scandals, the negative meaning will also be transferred to the endorsed brand and cause a decline in consumer's attitude towards the brand (Till \& Shimp, 1998). The worse news is that researchers Campbell and Warren (2012) found negative associations may be more likely to be transferred than positive associations. They conducted three studies and all of them showed that the negative personalities linked with the celebrity endorsers are more likely to be acquired by brands.

The potential risk behind celebrity endorsement requests marketers to be well-prepared and able to respond properly once any unexpected bad news about the celebrity endorser breaks out. The wisdom of coping with the crisis of the endorser determines whether the scandal will cause damage to or even become a PR crisis of the innocent brand itself. Despite the significance of understanding communication strategies related to celebrity endorsement crisis, few studies have focused on this aspect. The nature of different types of scandals, public perceptions, and corresponding solutions that 
brands should adopt remain unclear (Jiang, Huang, Wu, Choy, \& Lin, 2015).

Furthermore, the importance of cultural differences in communication has been emphasized and proved by many scholars (Ji et al., 2010; Ting-Toomey \& Dorjee, 2018). Past literature on crisis communication, however, was mainly constructed based on the experience of Western society due to the more mature business development and more advanced theoretical level of the Western. Given that Chinese culture is fundamentally different from Western culture (Hall \& Ames, 1995), as well as China's continuously rising economic and cultural power nowadays (Jiang et al., 2015), it is essential to investigate the characteristics of crisis management strategies in the distinctive Chinese cultural context.

Besides the lack of research focusing on response strategy and based on Chinese society, another problem is that many studies of crisis communication adopted experimental methodology (Coombs \& Holladay, 2014; Gupta, 2009; Jiang et al., 2015), thus the external validity cannot be assured. Under this circumstance, research that draws conclusions from examining and analyzing real-life cases shall be a necessary supplement. Social media shall be an appropriate platform to observe the brands' response and public's attitude because it has developed into a vitally important space for all companies trying to engage and communicate with Chinese consumers (Chiu, Ip, \& Silverman, 2012). Among all social network sites in China, Sina Weibo, an online microblogging platform, has been chosen in this study for its popularity. According to the report of Weibo Data Center (2019), it now has 462 million monthly active users and 200 million daily active users.

In conclusion, this paper aims to fill all the above-mentioned research gaps in the field of crisis communication and understand how brands in China should respond when their celebrity endorsers get involved in scandals by employing the methodology of case study and content analysis.

\section{Literature Review}

Crisis management consists of situation analysis, strategy selection and effectiveness evaluation (Jiang et al., 2015). This section will firstly summarize past literature on celebrity endorsement crisis. Then, factors that influence the severity of the crisis as well as Chinese public attitude towards the involved celebrity endorsers will be examined. The identified factors are the violation type of the scandal and public's attribution of responsibility. Furthermore. available response strategies will be discussed under Chinese culture context to see whether there exists a best or safest strategy. Finally, the literature on using social media to evaluate the effectiveness of crisis communication will be reviewed.

\subsection{Celebrity endorsement crisis}

Organizations and brands spend staggering money on hiring celebrity spokesperson for the purpose of associating their names or products with the celebrities' attractiveness, likeability, competence, and trustworthiness (Erdogan, 1999; Gass \& Seiter, 2015). The celebrity endorsement crisis refers to the celebrity's failure or damage in above dimensions (Jiang et al., 2015), which will harm his/her reputation, affect the credibility of the endorsement, and may further get the endorsed organization into trouble (Gass \& Seiter, 2015; Koo, Ruihley, \& Dittmore, 2012; Till \& Shimp, 1998).

Abundant research has proved the seriousness of celebrity endorsement crisis. Negative information about the celebrity detrimentally affects the endorsed brands (Zhou \& Whitla, 2013), lowers brand evaluation (Shang, 2012), and reduces purchase intention (Um \& Kim, 2016). A 25years-long study of Bartz, Molchanov and Stork (2013) investigated 93 cases of celebrity scandals happened between 1986 and 2011 and found that the scandals even had significant negative impacts on firm value. During the time around the scandals, the stock returns of firms having the involved celebrities as endorsers were statistically abnormal and significantly lower than usual time. Therefore, it is important for brands to a make proper and in-time decision when face such crisis to minimize both tangible and intangible damage. 


\subsection{Type of violation}

Communication is a field that always needs to adapt to various circumstances and never has a standard or universal formula. Different types of scandals have different levels of destructive power and request different solutions, thus understanding the type of violation is necessary. Past research mainly adopts the classification of competence violation and integrity violation, because these two are determinants of trustworthiness (Jiang et al., 2015; Kim, Dirks, Cooper, \& Ferrin, 2006). This paper, however, focuses only on integrity domain and divides the cases into violation of social legitimacy and violation of legal legitimacy, for the following two reasons:

First of all, competence violation is usually just negative information about the celebrity rather than a scandal, while integrity violation is greatly detrimental for trust and more likely to become a crisis (Kim et al., 2006). Although the celebrity's competence is related to his/her credibility (Koo et al., 2012), the disappointing performance can be forgiven by making apology, be understood by explaining the situation to the public, or be made up by winning the game next time (Sato, Ko, Park, $\&$ Tao, 2015). Brands can even use the accident to build a positive image by being supportive and caring to the incompetent endorser, such as what Nike did after its endorser Liu Xiang's unexpected withdrawal in London Olympic (Jiang et al., 2015). By contrast, it is very difficult to make up or restore trust if integrity is violated (Kim et al., 2006) because moral reputation is highly valued (Zhou \& Whitla, 2013).

The seriousness of integrity violation determines the focus of this study, and the two divisions, social legitimacy and legal legitimacy, respectively, are introduced to particularly adapt to the Chinese society. Under traditional Chinese culture context, when people evaluate the rationality and legitimacy of a behavior, a three-dimension standard will be adopted: Social ethics, reason, law, and among them reason in fact acts as a larger concept that contains both social ethics and law (Huang, Wang, Zhang, \& Zhou, 2010; Zhang \& Zhao, 2016). According to this culture value, Chinese scholars Huang et al. (2010) developed the classification of "social legitimacy violation" and "legal legitimacy violation" to analyze the entrepreneur's misbehaviors. As the public image of entrepreneur and that of celebrity endorser share similarities in terms of the representativeness and impact on the company's reputation, this paper borrowed these concepts for analyzing celebrities' scandals.

By definition, violation of social legitimacy refers to behaviors that contradict social norms, cultural values or public's moral principles. Violation of legal legitimacy means the behavior breaks national laws and regulations. It is worth mentioning that the boundary between these two categories is not always clear. Many cases in reality violate both social standards and legal rules (Zhang \& Zhao, 2016). For the convenience of research, cases discussed in this paper will be categorized according to their relative emphasis on violation type.

Unlike in Western culture, the status of the law is relatively low in the Chinese tradition. When there is a contradiction between social norm and law, Chinese people tend to value ethical consideration more than legal issue (Fan, 2003). Past literature on Chinese consumers' perception of celebrities at fault also confirms that behaviors violate social legitimacy, compared to legal misconducts, lead to more negative public image and worse reputation (Huang et al., 2010; Shang, 2012). In view of these findings, the following hypothesis is proposed:

H1: Celebrity endorsers who violate social legitimacy will find it more difficult to rebuild reputation among Chinese consumers than those who violate legal legitimacy.

\subsection{Attribution of responsibility}

Psychologist Heider (1958) firstly proposed the attribution theory, which suggests that people will attribute the cause of an event to internal/dispositional factors or external/situational factors. On this basis, Weiner (1985) made further development, connecting crisis with the attribution theory. The two key traits of crisis perfectly match with the two key characteristics that drive people to search for a cause: Unexpected and negative (Coombs, 2007; Weiner, 1985), thus the theory has always played a crucial role in studies about crisis communication, being applied to explain a variety of crisis types (Coombs, 2007). 
Celebrity endorsement crisis is no exception. Ample empirical and experimental research has found that people's attribution of crisis responsibility predicts their evaluation of the involved celebrities (Coombs \& Holladay, 1996; Zhang \& Zhao, 2016). When public attributes the cause of the negative event as external and outside of the celebrity's control, the celebrity will be seen as blameless and his/her reputation will not be much affected by the accident. In contrast, when the cause is attributed as internal and under the celebrity's control, he/she will be regarded as blameworthy and the scandal will have a great negative impact on his/her public image (Gupta, 2009; Louie \& Obermiller, 2002; Shang, 2012; Zhang \& Zhao, 2016). Research findings also indicate that endorsed brands will be negatively influenced only when the crisis responsibility is attributed internally to the endorser (Louie \& Obermiller, 2002; Um, 2013). Thus, the following hypothesis is proposed:

$\mathrm{H} 2$ : Internal attribution of crisis responsibility will have a more negative influence on the reputation of involved celebrity endorser than external attribution.

Introducing the attribution theory into the discussion of violation type, four possibilities of crisis situation appear: (1) Social legitimacy violation and internal attribution; (2) Social legitimacy violation and external attribution; (2) Legal legitimacy violation and internal attribution; (4) Legal legitimacy violation and external attribution. Based on the literature discussion of $\mathrm{H} 1$ and $\mathrm{H} 2$, it can be further inferred that the first situation has the biggest negative impact while the last situation has the smallest one, hence the following hypotheses:

$\mathrm{H} 2 \mathrm{a}$ : The reputation of the celebrity endorser is most damaged when the scandal violates social legitimacy and the responsibility is attributed to internal factors.

$\mathrm{H} 2 \mathrm{~b}$ : The reputation of the celebrity endorser is least damaged when the scandal violates legal legitimacy and the responsibility is attributed to external factors.

\subsection{Strategy of response}

Current literature on the recommended response strategy of celebrity endorsement crisis demonstrates a confusing pattern, and there are two main considerations in this aspect: (1) Whether to keep or dismiss the celebrity endorser; (2) Whether to indicate attitude or remain silent towards the scandal.

When confronted by a celebrity endorsement crisis, it is an unavoidable question for brands to decide whether to continue the endorsement contract or not (Louie \& Obermiller, 2002). Existed research conclusions, however, are contradicting. A considerable amount of research believes that an immediate termination is necessary to disassociate with the disreputable endorser and minimize the negative influence on the company's image (Bartz et al., 2013; Gupta, 2009). On the other hand, however, some researchers put forward that this strategy may be not suitable for Chinese culture. As a collectivist society, China values harmony, loyalty, solidarity and relational tie (Ting-Toomey \& Dorjee, 2018), thus the distance strategy may be seen as an "abandon" to a certain extent and viewed negatively by Chinese consumers. Jiang et al. (2015) proposed inclusion strategy as a better choice for Chinese culture, which suggests organizations should treat the celebrity endorsers as in-group members and maintain the solidarity. Besides, there are also scholars who take an intermediate stance. Louie and Obermiller (2002) concluded that endorsers with low blame should be kept, while those with high blame should be dismissed. He (2015) claimed that brands must clearly disassociate with endorsers who conducted illegal behaviors, while can exercise discretion in dealing with immoral scandals.

Another important issue for brands to consider is whether to respond to the inquiry of media and public about brands' opinion on their endorser's negative event. Compared to the lively discussion of the last question, the academic literature here is almost blank. A few studies believe "silence is the worst option" (Harvard Business Review, 2019) and advice brands to respond one way or another (Coombs, 2008) as well as clearly show the company's attitude towards the incident (He, 2015; Zuo, 2009). The concept of "Golden 72 Hours" in rescue is also introduced to crisis communication to stress the timeliness of response. Regardless of crisis type and PR decision, firms are suggested to respond within three days (Harvard Business Review, 2019; He, 2015). In reality, however, brands 
do not seem to buy this advice. When facing a celebrity endorsement crisis, about sixty percent of companies chose to do nothing (Harvard Business Review, 2019), but the reasons behind this practical choice remain unclear.

Stand by or break up? Silence is gold or response is gold? To provide guidance to assist organizations with the selection of response strategy for celebrity endorsement crisis, the following research question is raised:

RQ1: How do brands typically respond to celebrity endorsement crisis?

\subsection{Evaluation of effectiveness}

As a field that is closely related to the real business world and highly practical, crisis communication calls for more empirical instead of experimental research to ensure the external validity of findings (Coombs \& Holladay, 2014; Gupta, 2009). Social media then becomes a critical channel for crisis communication (Coombs, 2008; Schultz, Utz, \& Göritz, 2011; Veil, Buehner, \& Palenchar, 2011). On the one hand, the public actively participate and express during a crisis on social media platforms (Frandsen \& Johansen, 2010; Jin, Liu, \& Austin, 2014). On the other hand, celebrities and organizations are increasingly using social media as communication tools. Online response, such as making an announcement, explaining, clarifying or apologizing on social media, now plays a more and more important role in their crisis management strategy (Coombs, 2008; Schultz, Utz, \& Göritz, 2011). Therefore, online postings, from both public and brands, have been regarded as valuable and "worthwhile objects of analysis" in research on the effectiveness of crisis communication (Jiang et al., 2015).

In China, Sina Weibo is one of the most popular social media platforms and, more importantly, the place where scandals usually outbreak (Zhao, 2018). Coombs (2008) argued that a response should be made on the same media as the crisis is unfold. Consistent with his argument, Chinese celebrities and corporations usually choose to respond on Weibo when crises happen (Zhao, 2018).

Therefore, the crisis-related Weibo postings shall be appropriate materials for academics and PR practitioners to evaluate the effectiveness of the crisis response strategy in China.

\section{Methodology}

Approaches adopted in this paper are case study and content analysis. Four cases of celebrity endorsement crisis that happened last year in China have been selected. Characteristics of these crises, their impact on the reputation of involved celebrities, and the response strategies of affected brands will be examined.

\subsection{Case selection}

Past research prefers analyzing those classical cases in history to conclude the experience. What crisis managers in various organizations will really meet and have to deal with in their daily practices, however, are more ordinary cases. Learning from cases that happened around recently may gain more insights as well as practical guidance. Therefore, this paper selected cases from influential scandals in 2018 based on two criteria: (1) Views of the scandal-related topics on Weibo are more than 100 million times; (2) The involved celebrity was endorsing famous brands when the scandal broke out. Four cases fit the two requirements, thus were chosen. Table 1 shows brief information about the cases: 
Table 1. Overview of cases.

\begin{tabular}{|c|c|c|c|}
\hline & Celebrity & Scandal & Endorsed Brands \\
\hline 1 & Joe Chen & $\begin{array}{c}\text { In the early morning of January 4th } 2018 \text {, Joe Chen was arrested in Taipei } \\
\text { for drunk driving. }\end{array}$ & COGI \\
\hline 2 & Yang Mi & $\begin{array}{l}\text { At a film promotion event in 2015, Yang Mi said that she had donated } \\
\text { cane sticks and braille typewriters to the blind children of Chengdu Special } \\
\text { Education School, but in March } 2018 \text { a news spreading online saying that } \\
\text { the donation had never really been implemented. For a time, rumors about } \\
\text { her fraudulent donation aroused concern on the Internet. }\end{array}$ & $\begin{array}{l}\text { Estee Lauder } \\
\text { Michael Kors } \\
\text { Joyoung }\end{array}$ \\
\hline 3 & Fan Bingbing & $\begin{array}{l}\text { Fan Bingbing was accused of evading millions of dollars in taxes. Tax } \\
\text { authorities confirmed her tax evasion to the public in October 2018, and } \\
\text { she was fined around } \$ 129 \text { million. }\end{array}$ & $\begin{array}{l}\text { Louis Vuitton } \\
\text { De Beers } \\
\text { Montblanc } \\
\text { Swisse }\end{array}$ \\
\hline 4 & Wu Xiubo & $\begin{array}{l}\text { In September, a social media post of actress Chen Yulin disclosed that she } \\
\text { and the married actor Wu Xiubo had been in love for seven years, which } \\
\text { means Wu had been cheating on his wife. Since then, the two sides, } \\
\text { together with their families, began arguing for several months. }\end{array}$ & $\begin{array}{c}\text { Ermenegildo } \\
\text { Zegna } \\
\text { Normalteck } \\
\text { Dessmann } \\
\text { Redmi } \\
\text { Anjuke } \\
\text { KIC }\end{array}$ \\
\hline
\end{tabular}

Due to the need of research, ideally the cases are supposed to match the cross-combination of the two violation types and the two responsibility attributions. The situation of violation type is perfectly desirable. Apparently, Joe Chen's drunk driving and Fan Bingbing's tax evasion are legal violations, while Yang Mi's fraudulent donation and Wu Xiubo's extramarital affair violate social legitimacy.

For the attribution of crisis responsibility, however, only the cause of Yang's case can be attributed to external factors. Yang did not directly contact the school in need. Instead, there was a middleman who brought about the donation. Therefore, the fraudulent donation was an oversight rather than an intentional or hypocritical choice. Except for this case, other scandals are hard to attribute responsibilities to factors outside of the celebrities' control, especially in legal violation cases. After examining all major crises in China in recent three years, it has to be admitted that scandals both violate legal legitimacy and are externally attributed are so rare that empirical research approach may not be applicable to verify H2b. Despite the regret, the selected cases are enough to analyze and draw meaningful findings. Table 2 exhibits the nature of the cases:

Table 2. Violation type and responsibility attribution of cases.

\begin{tabular}{cccc}
\hline & Case & Violation Type & Responsibility Attribution \\
\hline 1 & Joe Chen & Legal Legitimacy & Internal \\
\hline 2 & Yang Mi & Social Legitimacy & External \\
\hline 3 & Fan Bingbing & Legal Legitimacy & Internal \\
\hline 4 & Wu Xiubo & Social Legitimacy & Internal \\
\hline
\end{tabular}

\subsection{Data collection}

For each case, comments and reposts of the involved celebrity's official response to the scandal on Weibo have been collected, in order to investigate netizens' attitude. Advertisements, empty or irrelevant content, and repetitive comments were then filtered out by the researcher to gain more accurate results. 849 out of 1,387 original comments in Joe Chen's case, 2,620 out of 3,800 comments in Yang Mi's case, and 2,273 out of 4,756 comments in Fan Bingbing's case were finally used for analysis. Wu Xiubo's case is somewhat special because he himself did not make any response. Instead, the official Weibo account of his studio published two posts to respond to the crisis: one is a lawyer's statement, and the other is a statement of Wu's wife. Because the studio shall be the representative of $\mathrm{Wu}$ and his family, it is reasonable to treat the two posts in the same way as the other three celebrities' responding posts. After combing the comments under the two posts and cleaning data, 2,481 out of 4,255 comments remains for the research.

Besides the celebrities' responding posts, posts of brands that were being endorsed by these 
celebrities when crises broke out were also examined, to evaluate the impact on brands' reputation as well as the effectiveness of brands' crisis response strategy. Only four involved brands chose to keep past promotion posts related to the endorsers and continue featuring them in other posts after the crises: COGI endorsed by Joe Chen, and Estee Lauder, Michael Kors, Joyoung endorsed by Yang Mi. To see whether the decision of keeping the endorser affected the brand reputation or not, comments and reposts of these brands' nearest Weibo posts to the crises that featured the endorsers were collected. After sorting out, 365 out of 794 comments of COGI, 1,050 out of 2,915 comments of Estee Lauder, 430 out of 1,110 comments of Michael Kors, and 40 out of 48 comments of Joyoung remains for analysis. Among them, Joyoung's post was published during the crisis, while the other three brands chose to post the celebrity-related content one month after the end of the crises.

\subsection{Content analysis}

The collected Weibo content was analyzed in two dimensions: Keywords extraction and sentiment analysis. The keyword indicates netizens' focus of attention, while sentiment demonstrates their emotional attitudes.

For keywords extraction, Chinese word segmentation was conducted, then meaningless words, such as auxiliary words, prepositions and pronouns, were filtered out. Lastly, the most frequently mentioned words were exhibited in the format of word clouds to clearly show the pattern. As for the sentiment analysis, each comment was categorized into one of positive, neutral, and negative, based on the expressed attitude. According to the proportion of each emotional type in all comments of a post, the general public attitude towards the post can be concluded.

\section{Findings}

\subsection{Public perception of the crises}

Among the four cases, the one of Joy Chen and the one of Yang Mi similarly received extremely positive feedbacks. For the former, around 95 percent of people expressed understanding, forgiveness or supports $(81 \%$ positive and $14 \%$ neutral), and only 5 percent left negative comments. The keywords extracted are also desirable. "love", "support", "miss", "cheer up"are most frequently mentioned.

In Yang Mi's case, although more negative responses were found (around 12\%), there are also more positive comments (around 84\%) at the same time. Compared to Chen's case, people here seem to care more about objective facts rather than subjective feelings, as the keywords are "donation", "children", "progress", "fault".

Fan Binging was not as lucky as them. Public attitude towards her apology was mixed, with some people strongly supporting her and at the same time another group believing that she was guilty beyond forgiveness. This contradiction is clearly shown in the sentiment analysis, as the proportions of positive comments (40\%) and negative comments (41\%) are almost the same and both very large. The word cloud also demonstrates this characteristic by having both "cheer up"and "interesting"on top positions.

Wu Xiubo's extramarital affair received an overwhelming negative response, with more than 70 percent of people strongly criticizing his immoral behaviors. Only 15 percent of netizens thought his fault was not that serious and could be forgiven. The most frequently used word in comments is "scumbag".

\subsection{Violation type and responsibility attribution}

The event causes of Joy Chen, Fan Bingbing and Wu Xiubo all should be attributed internally to themselves. The results, however, were quite different. The former two violated legal legitimacy and were forgiven by more than half of the public after responding on Weibo. Wu Xiubo violated social legitimacy and posted two statements to respond, but nearly three-quarters of netizens still viewed him as an immoral person. Their different situations confirm that it may be more difficult for social 
legitimacy violators to rebuild reputation among Chinese public than legal legitimacy violators. Thus, H1 is supported.

On the other hand, Yang Mi's fraudulent donation also violated social legitimacy, but her situation was much better than Wu Xiubo as well. Almost 85 percent of people thought the scandal was an overlook that was understandable and could be perfectly made up by Yang's later donations, while the majority of netizens believed $\mathrm{Wu}$ was dishonest, condemned him and called for a boycott of him. It is then quite clear that internal attribution of crisis responsibility will cause much more negative attitude on involved celebrities than external attribution. Thus, $\mathrm{H} 2$ is supported.

Another conclusion also can be drawn from Wu Xiubo's devastating scandal: It probably is the worst situation if the crisis belongs to social legitimacy violation and is attributed to internal causes by the public. As the only one in the four cases that fits in both of the two conditions, Wu's most greatly damaged reputation is not a surprise. In other words, H2a is well supported in this research. For $\mathrm{H} 2 \mathrm{~b}$, as explained in the section of case selection, this research cannot test its validity, due to the difficulty in finding empirical cases that satisfy both legal legitimacy violation and external attribution.

\subsection{Response strategy}

The crisis response strategies adopted by all affected brands in the four cases have been examined, including the continuation of contract and actions taken. Table 3 shows the summary:

Table 3. Brands' response strategy

\begin{tabular}{|c|c|c|c|c|}
\hline & Celebrity & Endorsed Brands & Endorsement Contract & Action \\
\hline 1 & Joe Chen & COGI & Maintain & $\begin{array}{l}\text { Celebrity-related post was stopped during the } \\
\text { crisis and resumed in February. }\end{array}$ \\
\hline \multirow{3}{*}{2} & \multirow{3}{*}{ Yang Mi } & Estee Lauder & \multirow{3}{*}{ Maintain } & Celebrity-related promotion was stopped \\
\hline & & Michael Kors & & during the crisis and resumed in May. \\
\hline & & Joyoung & & $\begin{array}{c}\text { Keep publishing celebrity-related posts during } \\
\text { the crisis }\end{array}$ \\
\hline \multirow{4}{*}{3} & \multirow{4}{*}{$\begin{array}{c}\text { Fan } \\
\text { Bingbing }\end{array}$} & Louis Vuitton & \multirow{2}{*}{ Not Sure } & \multirow{2}{*}{ No celebrity-related posts after the crisis } \\
\hline & & De Beers & & \\
\hline & & Montblanc & \multirow{2}{*}{ Terminated } & \multirow{2}{*}{$\begin{array}{l}\text { Announced the termination of the celebrity } \\
\text { endorsement in response to media inquiries. }\end{array}$} \\
\hline & & Swisse & & \\
\hline \multirow{5}{*}{4} & \multirow{5}{*}{ Wu Xiubo } & $\begin{array}{c}\text { Ermenegildo Zegna } \\
\text { Normalteck }\end{array}$ & Terminated & All celebrity-related posts were deleted \\
\hline & & Dessmann & \multirow{4}{*}{ Not Sure } & \multirow{4}{*}{ No celebrity-related posts after crisis } \\
\hline & & Redmi & & \\
\hline & & Anjuke & & \\
\hline & & $\mathrm{KIC}$ & & \\
\hline
\end{tabular}

In terms of whether to continue the endorsement contract, the two endorsers who received relatively positive feedback from netizens, Joy Chen and Yang Mi, were able to keep all their contracts. In contrast, the other two, who got more negative comments, lost all brand partners (although some brands have not clearly indicated the termination of contracts, the two celebrities have been absent from all promotions and events for several months till now). Therefore, the determination of the partnership is neither the violation type nor the attributed causes, but the public's attitude. No matter the endorser breaks the law or against social norms, no matter the scandal is caused by the endorser himself/herself or factors beyond his/her control, brands can keep the endorser as long as consumers respond positively to their crisis management approaches.

The brands that chose to maintain the endorsement indeed gained desirable feedback. The postcrisis Weibo posts featuring the involved celebrities of COGI, Michael Kors and Estee Lauder all received more than 85 percent of positive comments, and the former two had almost zero negative feedbacks. After reviewing extracted keywords, it is found that few people would mention the previous scandals or express dissatisfaction towards the endorsers. Instead, consumers focused more on the promotion content or the good appearance of the endorsers, and sometimes fans of the 
endorsers would appreciate that brands did not "abandon" their idols. "love", "beautiful", "thanks"was frequently mentioned in the comments.

An exception is Joyoung's post that mentioned Yang Mi. The percentage of positive comments was barely over half, and around 30 percent of consumers expressed doubts about the endorser. "Fraudulent donation" and "endorser" were mentioned by many netizens.

What makes Joyoung different from other three brands is that the post was published during the crisis instead of after the crisis. COGI, Michael Kors and Estee Lauder all began to post the endorserrelated content again one month after the celebrities' official response. In the new media age, one month is enough for a scandal to calm down and to let the public shift attention. Therefore, the scandals did not bring much trouble to the brands. Joyoung, however, chose a time when the public were angry about and highly concerning the incident, thus just got in the line of fire.

Not only brands continually using the celebrity endorser are silent during crises, brands that decide to disassociate with the celebrity also prefer action in silence. No brands affected by Fan Bingbing or $\mathrm{Wu}$ Xiubo actively express any attitude or make any statement. Some of them quietly deleted all past posts that mentioned the celebrities. Some said nothing and did nothing, just not posting the celebrityrelated content anymore. to solve the crisis. Montblanc and Swisse indicated the termination of Fan's endorsements, but only in response to media's inquiries rather than official statements. Although it is hard to say whether an active response will be better or not, at least the "silence strategy" seems do not bring any damage to the brand.

Therefore, the answer of RQ1 is that brands in China typically keep endorsers who receive positive public feedback and dismiss those with negative feedback, regardless of the nature of the scandals. And no matter continuation or termination of the contract, the brands tend to adopt "silence strategy" during the celebrity endorsement crisis.

\section{Conclusion and discussion}

\subsection{Violation type in the Chinese context}

Besides the popular classification of competence violation and integrity violation in research on celebrity endorsement crisis, a further subdivision of integrity violation deserves attention due to the great destructive power of this violation type (Jiang et al., 2015). Under traditional Chinese culture context, people tend to evaluate a behavior by the dimension of social ethics and law (Huang et al., 2010; Zhang \& Zhao, 2016). Meanwhile, Chinese people highly value morality (Huang, 2010, cited in Jiang et al., 2015) and even attach more significance to social ethics than the law (Fan, 2003).

Therefore, for brands dealing with celebrity endorsement crisis in China, only knowing whether the scandal violated integrity or not is not enough. It must be recognized whether the involved endorser violated social legitimacy or legal legitimacy. Usually speaking, crisis managers should be more cautious when coping with social legitimacy violation because of its more negative impact on reputation, as demonstrated in this research.

\subsection{Attribution theory in crisis management}

Attribution theory has been widely adopted in the analysis of crisis communication (Coombs, 2007). This research verifies previous findings in the field of celebrity endorsement crisis: Internal attribution of crisis responsibility causes a more negative influence on reputation than external attribution. Even if the scandal violated social legitimacy, it is not necessarily damaging as long as the celebrity can prove it was caused by external factors out of his/her control.

The finding also implies that crisis managers in real-life practices may respond (no matter apologize or explain) with external attributions and do not need to worry about being perceived as insincerity. This suggestion confirms with the research conclusion of Kim et al. (2006) that argues any mitigating response is worthwhile. 


\subsection{Factors influencing the seriousness of crisis}

It has been supported by this research that violation type and crisis responsibility attribution are two key factors influencing the seriousness of a crisis. A scandal both violates social legitimacy and is attributed to internal causes will be most damaging to the reputation of involved celebrity.

There must also be other factors at work, however. The tax evasion of Fan Bingbing and the drunk driving of Joy Chen are of the same nature in regard of violation type and responsibility attribution, but the latter received far more positive public feedback than the former. As a result, Chen was kept as COGI's endorser while all brands endorsed by Fan chose to disassociate with her. Thus, there is still much space in research on characteristics of celebrity endorsement crisis waiting for further exploration.

\subsection{Decision on termination of the endorsement}

Past research conclusions are inconsistent in whether to continue the endorsement contract with a celebrity involved in scandals or not. Some suggested an immediate termination with a disreputable endorser (Bartz et al., 2013; Gupta, 2009), while others argued maintaining solidarity during hard times is highly valued in Chinese society (Ting-Toomey \& Dorjee, 2018). Some supported keeping endorsers to whom the crisis responsibility is not mainly attributed and dismissing endorsers that are blameworthy (Obermiller, 2002), while others believed it is legal legitimacy violation the most intolerable (He, 2015).

Findings of this research reveal that the most important determination shall be the public attitude towards the involved celebrity endorser. The decision should not be made solely according to any of social culture context, violation type or responsibility attribution. Instead, it is wise to pay attention to and evaluate public sentiments to decide whether to terminate the partnership or not correspondingly.

\subsection{Silence strategy in celebrity endorsement crisis}

Contrary to many opinions emphasizing the significance of brand's active and quick response after a celebrity endorsement crisis broke out (Coombs, 2008; Harvard Business Review, 2019; He, 2015; Zuo, 2009), this research supports the "silence strategy".

The active response strategy as well as the "Golden 72 Hours" principle should be adopted and followed when a celebrity manages his/her own crisis or when a brand deals with a scandal of its own product/company. For celebrity endorsement crisis, however, it may be safer for brands to be silent. After all, the brand is not the main focus of public attention during the incident, thus it is unwise to draw fire by a public statement or an expression of attitude. Brands deciding to terminate the endorsement shall do it quietly to avoid being criticized as "kicking down the ladder". Brands who choose to keep the celebrity endorser are also supposed to be silent during the crisis to lie low and not be associated with the scandal. This research suggests that one month after the celebrity's official response may be an appropriate time span for the incident to calm down and public attention to be diverted, so brands can begin featuring the endorsers again.

\subsection{Celebrity endorsement crisis management}

Together with the pervasiveness of celebrity endorsement in the marketing and advertising industry comes the risk of being negatively affected by the endorser's scandal. This research provides practical guidance for brands to manage celebrity endorsement crisis in China. Firstly, crisis managers shall have a judgment of the nature and seriousness of the crisis. The violation type and crisis responsibility attribution are two important factors that should be taken into account to anticipate the blameworthiness of the involved endorser as well as the extent of negative impact on reputation. Secondly, social media discussion and public sentiments shall be paid attention to, so that brands can evaluate public attitude towards the celebrity and make the decision on whether to continue the endorsement contract or not accordingly. Lastly, the brand shall keep silent about the endorser during the crisis, no matter what decision on the endorsement it had made. It may begin reusing the endorser 
one month after the incident. In this way, a brand shall be able to avoid being associated with the negative information about its endorser.

What is worth mentioning here is the prevention of crisis. On the one hand, brands are supposed to conduct comprehensive background investigations on the endorser candidate and clearly list all behavior restraints as well as relevant compensations on the endorsement contract. On the other hand, PR practitioners have to keep an eye on their endorsers in order to notice, solve, or prepare for any potential crisis as early as possible.

\section{Limitations}

This paper mainly examined two key factors, that is, violation type and crisis responsibility attribution, which influence the seriousness of a celebrity endorsement crisis, and is not exclusive and comprehensive. There are many other possible factors, such as the original public perception of the celebrity endorser, reputation and popularity of the brand, sensitivity of the involved topic (e.g., Taiwan may be a sensitive topic than the U.S. for Chinese public), and whether the celebrity apologized or not. The influence power and pattern of these factors require future research to explore.

Besides, one hypothesis could not be tested in this paper due to the lack of real-life cases. Scandals that violate legal legitimacy and can be attributed to external causes are rare in reality, thus whether this kind of incident is least damaging on reputation or not probably can only be tested through experiments. Future studies may test this hypothesis by designing cases that meet the conditions.

The final limitation lies in the data sample. All Weibo data used in this research were automatically collected by a web crawler software program. Due to the imperfections of the software as well as restrictions of Sina Weibo on data crawling, only a proportion of comments and reposts can be collected. Future researchers may adopt more sophisticated programs to gain more complete data. Content on other popular Chinese social media platforms, such as WeChat public accounts and Zhihu, may also be collected and analyzed to make either complement or comparison.

\section{References}

[1] Bartz, S., Molchanov, A., \& Stork, P. A. (2013). When a celebrity endorser is disgraced: A twentyfive-year event study. Marketing Letters, 24(2), 131-141.

[2] Campbell, M. C., \& Warren, C. (2012). A risk of meaning transfer: Are negative associations more likely to transfer than positive associations?. Social influence, 7(3), 172-192.

[3] Chan, K., Leung Ng, Y., \& Luk, E. K. (2013). Impact of celebrity endorsement in advertising on brand image among Chinese adolescents. Young Consumers, 14(2), 167-179.

[4] Chiu, C., Ip, C., \& Silverman, A. (2012). Understanding social media in China. McKinsey Quarterly, 2(2012), 78-81.

[5] Coombs, W. T. (2007). Attribution theory as a guide for post-crisis communication research. Public Relations Review, 33(2), 135-139.

[6] Coombs, W. T. (2008). Crisis communication. The International Encyclopedia of Communication.

[7] Coombs, W. T., \& Holladay, S. J. (1996). Communication and attributions in a crisis: An experimental study in crisis communication. Journal of public relations research, 8(4), 279-295.

[8] Coombs, W. T., \& Holladay, S. J. (2014). How publics react to crisis communication efforts: Comparing crisis response reactions across sub-arenas. Journal of Communication Management, 18(1), 40-57. 
[9] DoMarketing. (2012). Insider view and reflection on celebrity endorsement in China TV commercials. Retrieved from http://www.domarketing.org/html/2012/ad_0601/4744.html

[10]Erdogan, B. Z. (1999). Celebrity endorsement: A literature review. Journal of marketing management, 15(4), 291-314.

[11]Fan, Y. (2003). Conflict and coordination of social norm, reason and law. Retrieved from http://www.cetv.com/lm/131/61/85930.html

[12]Frandsen, F., \& Johansen, W. (2010). Apologizing in a globalizing world: crisis communication and apologetic ethics. Corporate Communications: An International Journal, 15(4), 350-364.

[13]Gass, R. H., \& Seiter, J. S. (2015). Persuasion: Social Influence and Compliance Gaining. Routledge.

[14]Gupta, S. (2009). How do consumers judge celebrities' irresponsible behavior? An attribution theory perspective. The Journal of Applied Business and Economics, 10(3), 1.

[15]Hall, D. L., \& Ames, R. T. (1995). Anticipating China: Thinking through the narratives of Chinese and Western culture. SUNY Press.

[16]Harvard Business Review. (2019). When scandal engulfs a celebrity endorser. Retrieved from https://hbr.org/2019/05/when-scandal-engulfs-a-celebrity-endorser

[17]He, Y. (2015). Response strategy of celebrity endorser's native crisis. Youth Journalist, (30), 101102.

[18]Heider, F. (1958). The psychology of interpersonal relations. New York: Wiley.

[19]Huang, J., Wang, X., Zhang, S., \& Zhou, N. (2010). The effect of entrepreneurs' feeling-hurting and their law-violating behaviors on the brand image. Management World, 5, 96-107.

[20]Ji, Y. G., Hwangbo, H., Yi, J. S., Rau, P. P., Fang, X., \& Ling, C. (2010). The influence of cultural differences on the use of social network services and the formation of social capital. Intl. Journal of Human-Computer Interaction, 26(11-12), 1100-1121.

[21]Jiang, J., Huang, Y. H., Wu, F., Choy, H. Y., \& Lin, D. (2015). At the crossroads of inclusion and distance: Organizational crisis communication during celebrity-endorsement crises in China. Public Relations Review, 41(1), 50-63.

[22]Jin, Y., Liu, B. F., \& Austin, L. L. (2014). Examining the role of social media in effective crisis management: The effects of crisis origin, information form, and source on publics' crisis responses. Communication Research, 41(1), 74-94.

[23]Louie, T. A., \& Obermiller, C. (2002). Consumer response to a firm's endorser (dis) association decisions. Journal of advertising, 31(4), 41-52.

[24]Kim, P. H., Dirks, K. T., Cooper, C. D., \& Ferrin, D. L. (2006). When more blame is better than less: The implications of internal vs. external attributions for the repair of trust after a competence-vs. integrity-based trust violation. Organizational Behavior and Human Decision Processes, 99(1), 49-65.

[25]Koo, G. Y., Ruihley, B. J., \& Dittmore, S. W. (2012). Impact of perceived on-field performance on sport celebrity source credibility. Sport Marketing Quarterly, 21(3), 147.

[26] McCracken, G. (1989). Who is the celebrity endorser? Cultural foundations of the endorsement process. Journal of consumer research, 16(3), 310-321. 
[27]Miller, F. M., \& Allen, C. T. (2012). How does celebrity meaning transfer? Investigating the process of meaning transfer with celebrity affiliates and mature brands. Journal of Consumer Psychology, 22(3), 443-452.

[28] Sato, S., Ko, Y. J., Park, C., \& Tao, W. (2015). Athlete reputational crisis and consumer evaluation. European Sport Management Quarterly, 15(4), 434-453.

[29] Schultz, F., Utz, S., \& Göritz, A. (2011). Is the medium the message? Perceptions of and reactions to crisis communication via twitter, blogs and traditional media. Public relations review, 37(1), 20-27.

[30] Shang, D. (2012). How do scandals of celebrity endorsers affect consumer attitude? (Master's thesis).

[31]Till, B. D., \& Shimp, T. A. (1998). Endorsers in advertising: The case of negative celebrity information. Journal of advertising, 27(1), 67-82.

[32]Ting-Toomey, S., \& Dorjee, T. (2018). Communicating across cultures. Guilford Publications.

[33]Um, N. H. (2013). Celebrity scandal fallout: How attribution style can protect the sponsor. Psychology \& Marketing, 30(6), 529-541.

[34]Um, N. H., \& Kim, S. (2016). Determinants for effects of celebrity negative information: when to terminate a relationship with a celebrity endorser in trouble?. Psychology \& Marketing, 33(10), 864-874.

[35]Veil, S. R., Buehner, T., \& Palenchar, M. J. (2011). A work-in-process literature review: Incorporating social media in risk and crisis communication. Journal of contingencies and crisis management, 19(2), 110-122.

[36] Weibo Data Center. (2019). 2018 Weibo users trends report. Retrieved from http://data.weibo.com/report/reportDetail?id=433

[37] Weiner, B. (1985). An attributional theory of achievement motivation and emotion. Psychological Review, 92(4), 548.

[38]Zhang, S., \& Zhao, M. (2016). The influence on brand attitude of the negative behavior of star endorsement_—From the perspective of moral evaluation. Social Sciences of Beijing, (9), 9198.

[39]Zhao, J. (2018). Explore celebrity's Weibo crisis management strategy in we media era. Modern Business Magazine.

[40]Zhou, L., \& Whitla, P. (2013). How negative celebrity publicity influences consumer attitudes: The mediating role of moral reputation. Journal of Business Research, 66(8), 1013-1020.

[41]Zuo, L. (2009). The selection and crisis management of celebrity endorsers. Management \& Technology of SME, (7), 110-111. 